\title{
Video Article \\ Efficient Derivation of Human Neuronal Progenitors and Neurons from Pluripotent Human Embryonic Stem Cells with Small Molecule Induction
}

\author{
Xuejun H. Parsons ${ }^{1,2}$, Yang D. Teng ${ }^{3,4}$, James F. Parsons ${ }^{1,2}$, Evan Y. Snyder ${ }^{1,2,5}$, David B. Smotrich ${ }^{1,2,6}$, Dennis A. Moore ${ }^{1,2}$ \\ ${ }^{1}$ San Diego Regenerative Medicine Institute \\ ${ }^{2}$ Xcelthera \\ ${ }^{3}$ Department of Neurosurgery, Harvard Medical School \\ ${ }^{4}$ Division of SCI Research, VA Boston Healthcare System \\ ${ }^{5}$ Program in Stem Cell \& Regenerative Biology, Sanford-Burnham Medical Research Institute \\ ${ }^{6}$ La Jolla IVF
}

Correspondence to: Xuejun H. Parsons at parsons@SDRMI.org

URL: https://www.jove.com/video/3273

DOI: doi:10.3791/3273

Keywords: Neuroscience, Issue 56, stem cell, human embryonic stem cell, human, neuronal progenitor, neuron, human pluripotent cell, neuronal differentiation, small molecule induction, cell culture, cell therapy

Date Published: $10 / 28 / 2011$

Citation: Parsons, X.H., Teng, Y.D., Parsons, J.F., Snyder, E.Y., Smotrich, D.B., Moore, D.A. Efficient Derivation of Human Neuronal Progenitors and Neurons from Pluripotent Human Embryonic Stem Cells with Small Molecule Induction. J. Vis. Exp. (56), e3273, doi:10.3791/3273 (2011).

\section{Abstract}

There is a large unfulfilled need for a clinically-suitable human neuronal cell source for repair or regeneration of the damaged central nervous system (CNS) structure and circuitry in today's healthcare industry. Cell-based therapies hold great promise to restore the lost nerve tissue and function for CNS disorders. However, cell therapies based on CNS-derived neural stem cells have encountered supply restriction and difficulty to use in the clinical setting due to their limited expansion ability in culture and failing plasticity after extensive passaging ${ }^{1-3}$. Despite some beneficial outcomes, the CNS-derived human neural stem cells (hNSCs) appear to exert their therapeutic effects primarily by their non-neuronal progenies through producing trophic and neuroprotective molecules to rescue the endogenous cells ${ }^{1-3}$. Alternatively, pluripotent human embryonic stem cells (hESCs) proffer cures for a wide range of neurological disorders by supplying the diversity of human neuronal cell types in the developing CNS for regeneration ${ }^{1,4-7}$. However, how to channel the wide differentiation potential of pluripotent hESCs efficiently and predictably to a desired phenotype has been a major challenge for both developmental study and clinical translation. Conventional approaches rely on multi-lineage inclination of pluripotent cells through spontaneous germ layer differentiation, resulting in inefficient and uncontrollable lineage-commitment that is often followed by phenotypic heterogeneity and instability, hence, a high risk of tumorigenicity ${ }^{7-10}$. In addition, undefined foreign/animal biological supplements and/or feeders that have typically been used for the isolation, expansion, and differentiation of hESCs may make direct use of such cell-specialized grafts in patients problematic ${ }^{11-13}$. To overcome these obstacles, we have resolved the elements of a defined culture system necessary and sufficient for sustaining the epiblast pluripotence of hESCs, serving as a platform for de novo derivation of clinicallysuitable hESCs and effectively directing such hESCs uniformly towards clinically-relevant lineages by small molecules ${ }^{14}$ (please see a schematic in Fig. 1). Retinoic acid (RA) does not induce neuronal differentiation of undifferentiated hESCs maintained on feeders ${ }^{1,14}$. And unlike mouse ESCs, treating hESC-differentiated embryoid bodies (EBs) only slightly increases the low yield of neurons $s^{1,14,15}$. However, after screening a variety of small molecules and growth factors, we found that such defined conditions rendered retinoic acid (RA) sufficient to induce the specification of neuroectoderm direct from pluripotent hESCs that further progressed to neuroblasts that generated human neuronal progenitors and neurons in the developing CNS with high efficiency (Fig. 2). We defined conditions for induction of neuroblasts direct from pluripotent hESCs without an intervening multi-lineage embryoid body stage, enabling well-controlled efficient derivation of a large supply of human neuronal cells across the spectrum of developmental stages for cell-based therapeutics.

\section{Video Link}

The video component of this article can be found at https://www.jove.com/video/3273/

Protocol

\section{Solution and Media Preparation}

1. Gelatin coating solution: $0.1 \%(\mathrm{w} / \mathrm{v})$ gelatin in $\mathrm{ddH}_{2} \mathrm{O}$, autoclaved and store at $4^{\circ} \mathrm{C}$.

2. Matrigel coating solutions. Stock solution: slow thaw Matrigel $(10 \mathrm{ml})$ at $4^{\circ} \mathrm{C}$ overnight, add $10 \mathrm{ml}$ ice-cold DMEM or DMEM/F12, mix well and aliquot $1 \mathrm{ml} /$ tube underneath sterilized tissue culture hood, store at $-20^{\circ} \mathrm{C}$. Working solution: slow thaw $1 \mathrm{ml}$ Matrigel aliquot at $4{ }^{\circ} \mathrm{C}$ for $1-2$ hour, transfer to $14 \mathrm{ml}$ chilled DMEM or DMEM/F12 and mix well underneath sterilized tissue culture hood immediately before coating.

3. Human laminin coating solution: dilute $1 \mathrm{ml}$ human laminin solution $\left(0.5 \mathrm{mg} / \mathrm{ml}\right.$ in Tris Buffered $\mathrm{NaCl}$, store at $-80^{\circ} \mathrm{C}$, slow thaw at $4{ }^{\circ} \mathrm{C}$ for $1-2$ hour) with ice-cold DMEM or DMEM/F12 to $12.5 \mathrm{ml}$ working solution $(40 \mu \mathrm{g} / \mathrm{ml})$ underneath sterilized tissue culture hood immediately before coating. 
4. Growth factor stock solutions (500-1000X): dissolve growth factor at $10 \mu \mathrm{g} / \mathrm{ml}$ in sterilized buffer $(0.5 \% \mathrm{BSA}, 1.0 \mathrm{mM} \mathrm{DTT}, 10 \% \mathrm{glycerol}$, 1XPBS) and store as $50-100 \mu \mathrm{l} /$ tube aliquots at $-80^{\circ} \mathrm{C}$.

5. All-trans-retinoic acid working solution (1000X): $10 \mathrm{mM}$ in DMSO, store in aliquots at $-80^{\circ} \mathrm{C}$.

6. HESC media: DMEM/F12 or KO-DMEM (80\%), KO serum replacement (20\%), L-alanyl-L-gln or L-gln (2 mM), MEM nonessential amino acids (MNAA, 1X), and $\beta$-Mercaptoethanol $(100 \mu \mathrm{M})$, filtered and store at $4^{\circ} \mathrm{C}$, supplemented with $20 \mathrm{ng} / \mathrm{ml}$ bFGF before use. Or replacing "knock out (KO) serum replacement" with defined components: DMEM/F12 or KO-DMEM (100\%), L-alanyl-L-gln or L-gln (2 mM), MNAA (1X), MEM essential amino acids (MEAA, 1X), and $\beta$-Mercaptoethanol $(100 \mu \mathrm{M})$, filtered and store at $4^{\circ} \mathrm{C}$, supplemented with bFGF $(20 \mathrm{ng} / \mathrm{ml})$, human insulin $(20 \mu \mathrm{g} / \mathrm{ml})$, ascorbic acid $(50 \mu \mathrm{g} / \mathrm{ml})$, human activin $A(50 \mathrm{ng} / \mathrm{ml})$, human albumin/Albumax $(10 \mathrm{mg} / \mathrm{ml})$, and human transferrin $(8 \mu \mathrm{g} / \mathrm{ml})$ before use.

7. NSC media: DMEM/F12 (100\%), N-2 supplement (1X), heparin $(8 \mu \mathrm{g} / \mathrm{ml})$.

\section{Plate Coating}

1. Coat plates with gelatin: add $2.5 \mathrm{ml} /$ well of gelatin solution to 6 well plates and incubate overnight in a $37^{\circ} \mathrm{C}$ humidified incubator.

2. Coat plates with laminin: chill gelatin-coated plates and remove gelatin, add $2.5 \mathrm{ml} /$ well Matrigel or human laminin coating working solution to pre-chilled gelatinized 6 -well plates and incubate at $4^{\circ} \mathrm{C}$ overnight.

\section{Passaging and Seeding Undifferentiated hESCs under Defined Conditions}

1. Allow hESC colonies grow to 5-7 days old, and take hESC culture plate to dissecting microscope (pre-warm dissecting stage to $37^{\circ} \mathrm{C}$ ) underneath dissecting sterilized hood.

2. Select hESC colonies to be split. Morphologically, these colonies should have $>75 \%$ undifferentiated hESCs (small compact cells), usually slightly opaque (not white-piled-up cells, not clear-differentiated cells) with defined edge underneath the dissecting microscope. Carefully outline the selected colonies and remove differentiated fibroblast layer surrounding the colony and all differentiated parts (if any) of the colony with the edge of P2 sterile pipette tip or pulled glass capillary. (Please note, pluripotent hESCs are at a transient stage, undergo spontaneous differentiation even under optimal conditions, although preferred, it's difficult to ascertain theses cells are $100 \%$ undifferentiated under dissecting microscope, $>75 \%$ undifferentiated are usually considered as the pass point. The differentiated cells usually will not seed and continue to grow, eliminated in the passaging process)

3. Remove the old media containing floating detached differentiated cells by aspirating. Wash with hESC media (without bFGF) once. Add 3 ml/ well fresh hESC media containing $20 \mathrm{ng} / \mathrm{ml} \mathrm{bFGF}$.

4. Cut the undifferentiated hESC colonies into small pieces, and detach with sterile pipette tip or pulled glass capillary.

5. Pool the media containing detached colony pieces together in a $50 \mathrm{ml}$ conical tube. Wash the plate once with $1 \mathrm{ml} / \mathrm{well} \mathrm{hESC} \mathrm{media}$ containing $20 \mathrm{ng} / \mathrm{ml} \mathrm{bFGF}$ and pool together.

6. Aspirate the Matrigel or human laminin solution from the coated fresh plates. Aliquot $4 \mathrm{ml} / \mathrm{well} \mathrm{hESC}$ media containing colony pieces to a 6 well plate. Gently transfer the plate to incubator without shaking and allow colony pieces seed overnight without disturbing in a humidified $37^{\circ} \mathrm{C}$ incubator with an atmosphere of $5 \% \mathrm{CO}_{2}$.

\section{Neural Induction of hESCs under Defined Culture System with Retinoic Acid}

1. At day 3 after seeding, remove most of old media from each well of the plate and leave enough media to allow $\mathrm{hESC}$ colonies to be submerged (never allow hESCs to dry out). Replace with $4 \mathrm{ml} /$ well fresh hESC media containing $20 \mathrm{ng} / \mathrm{ml} \mathrm{bFGF}$ and $10 \mu \mathrm{M}$ retinoic acid

2. Replace old media with fresh $\mathrm{hESC}$ media containing $20 \mathrm{ng} / \mathrm{ml} \mathrm{bFGF}$ and $10 \mu \mathrm{M}$ retinoic acid every other day, and allow neural-induced hESC colonies grow to day 7 or 8 . All the cells within the colony will undergo morphology changes to large differentiated cells that will continue to multiply. The colonies will increase in size to cover the plate by day 7 or 8 , and cells will begin to pile up in some areas of the colonies.

\section{Continuing Neuronal Differentiation in Suspension Culture}

1. Take hESC culture plate to dissecting microscope (pre-warm dissecting stage to $37^{\circ} \mathrm{C}$ ) underneath dissecting sterilized hood. Carefully outline the colonies and remove fibroblast layer surrounding the colony (differentiated cells migrated out of the colony) with the edge of P2 sterile pipette tip or pulled glass capillary.

2. Remove the old media containing floating detached fibroblast cells by aspirating. Wash with hESC media (without bFGF) once. Add $3 \mathrm{ml} / \mathrm{well}$ fresh hESC media (without bFGF).

3. Cut the neural-induced hESC colonies into small pieces, and detach with sterile pipette tip or pulled glass capillary.

4. Pool the media containing detached colony pieces together in a $50 \mathrm{ml}$ conical tube. Wash the plate once with $1 \mathrm{ml} / \mathrm{well} \mathrm{hESC} \mathrm{media}$ (without bFGF) and pool together.

5. Aliquot $4 \mathrm{ml} /$ well serum-free hESC media containing colony pieces to a 6 -well ultralow attachment plate and incubate in a $37^{\circ} \mathrm{C}$ humidified incubator to allow floating cellular clusters (neuroblasts) to form for 4-5 days.

\section{Neuronal Phenotype Maturation in Adhesive Culture}

1. Pool the media containing floating neuroblasts together in a $50 \mathrm{ml}$ conical tube. Centrifuge at $1400 \mathrm{rpm}$ for $5 \mathrm{~min}$. Aspirate the old media as much as you can and add equal amount of fresh NSC media containing VEGF (20 ng/ml), NT-3 (10 ng/ml), and BDNF (10 ng/ml).

2. Pipette up and down to mix floating neuroblasts and aliquot $4 \mathrm{ml} /$ well to 6 -well plates. The neuroblasts can also be seeded in a laminin/ collagen (Matrigel) or human laminin polymerized 3-dimensional matrix in serum-free NSC media containing VEGF (20 ng/ml), NT-3 (10 ng/ $\mathrm{ml})$, and BDNF (10 $\mathrm{ng} / \mathrm{ml})$. Transfer the plates to a $37^{\circ} \mathrm{C}$ humidified incubator to allow neuroblasts to attach overnight. 
3. Replace NSC media containing VEGF $(20 \mathrm{ng} / \mathrm{ml})$, NT-3 $(10 \mathrm{ng} / \mathrm{ml})$, and BDNF $(10 \mathrm{ng} / \mathrm{ml})$ every other day. Extensive networks of neuritebearing neuronal cells and pigmented cells will begin to appear within 2 weeks of continuous cultivation and increase in numbers with time, and could be sustained for over 3 months.

\section{Representative Results:}

Retinoic acid (RA) is rendered sufficient to induce hESCs maintained in the defined culture system to transition from pluripotency exclusively to a neuroectodermal phenotype (Fig. 2A). Upon exposure of undifferentiated hESCs to RA, all the cells within the colony will undergo morphology changes to large differentiated cells that cease expressing pluripotency-associated markers, as indicated by Oct-4, and begin expressing various neuroectoderm-associated markers, such as HNK1, AP2, and TrkC (Fig. 2B). These large differentiated cells will continue to multiply and the colonies will increase in size, proceeding spontaneously to express the early neuronal marker $\beta$-III-tubulin (Fig. 2B). The more mature neuronal marker Map-2 will begin to appear in areas of the colonies where cells have piled up (Fig. 2B). Coincident with the appearance of the neuroectodermal cells and neuronal differentiation, the neuronal specific transcriptional factor Nurr1, implicated in dopaminergic neuronal differentiation and activation of the tyrosine hydroxylase $(\mathrm{TH})$ gene ${ }^{16}$, will translocate to the nucleus (Fig. 2B). After detached, the RA-treated hESCs will form floating cellular clusters (neuroblasts) in a suspension culture to continue the neural differentiation process. Upon removal of bFGF and after permitting the neuroblasts to attach to a tissue culture plate or seeded in a laminin/collagen polymerized 3-dimensional matrix in a serum-free defined medium, $\beta$-III-tubulin- and Map-2-expressing, neurite-bearing cells and pigmented cells will begin to appear with a drastic increase in efficiency as compared to spontaneous multi-lineage differentiation of hESCs without treatment over the same time period, and could be sustained for over 3 months (Fig. 2C).
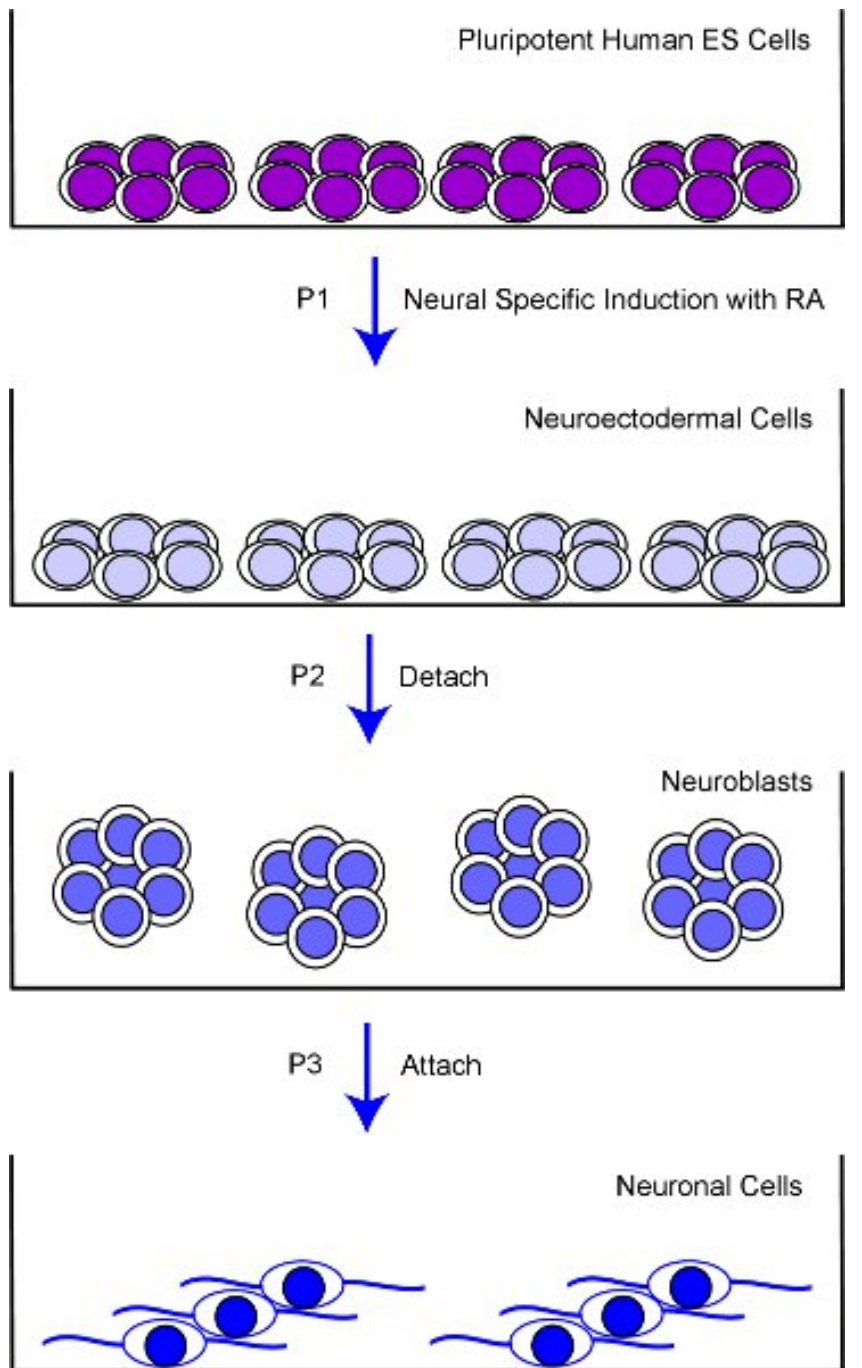

Figure 1 A schematic of well-controlled efficient induction of human pluripotent stem cells exclusively to a particular clinically-relevant lineage by simple provision of small molecules. 
A

\begin{tabular}{|c|c|c|c|c|}
\hline $\begin{array}{l}\text { Seeding in } \\
\text { Defined Culture }\end{array}$ & $\begin{array}{l}\text { Neural Induction } \\
\text { in Defined Culture }\end{array}$ & $\begin{array}{l}\text { Suspension } \\
\text { Culture }\end{array}$ & \multicolumn{2}{|l|}{$\begin{array}{l}\text { Neuronal Phenotype } \\
\text { Maturation in Attachment }\end{array}$} \\
\hline hESC Media + bFGF & hESC Media + bFGF + RA & hESC Media & \multicolumn{2}{|l|}{$\mathrm{NSC}$ Media + VEGF + NT-3 + BDNF } \\
\hline |Undifferentiated hESCs| & Neuroectodermal Cells & Neuroblasts & & Neuronal Cells \\
\hline 1 Day & & \multicolumn{3}{|c|}{ Day 28} \\
\hline
\end{tabular}

B

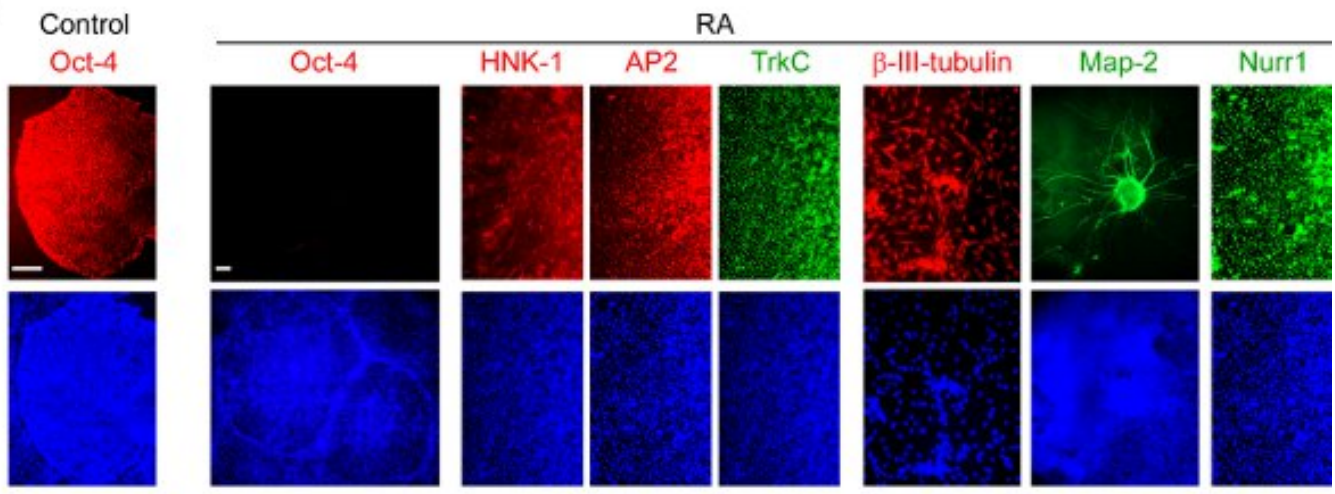

C

Phase

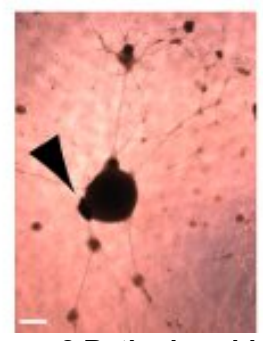

Phase

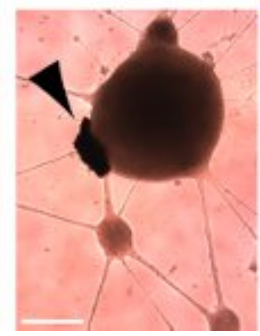

$\beta$-III-Tubulin

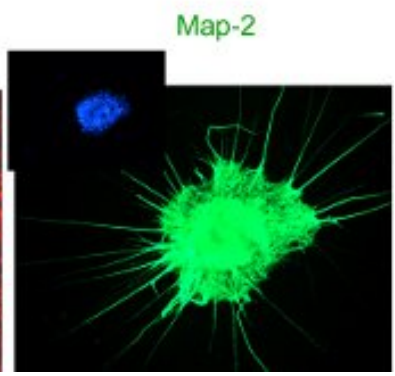

Figure 2 Retinoic acid induces neural lineage specification and neuronal progression direct of pluripotency under defined conditions.

(A) Schematic depicting of the protocol time line of directed neuronal differentiation of hESCs. (B) Upon exposure of undifferentiated hESCs to retinoic acid (RA) under the defined culture system, large differentiated Oct-4 (red) negative cells within the colony began to emerge, as compared to mock-treated (DMSO) hESCs as the control. RA-induced differentiated Oct-4-negative cells began to express HNK-1 (red), AP2 (red), TrkC (green), and then $\beta$-III-tubulin (red), consistent with early neuroectodermal differentiation. These cells continued to mature ultimately expressing the neuronal marker Map-2 (green), usually in areas where cells began to pile up. Coincident with the appearance of the neuroectodermal cells and neuronal differentiation, the neuronal specific transcriptional factor Nurr1 (green), implicated in dopaminergic neuronal differentiation and activation of the tyrosine hydroxylase (TH) gene, translocated to the nucleus. All cells are shown by DAPI staining of their nuclei (blue). (C) RA treatment induces differentiation towards a neuronal lineage with high efficiency as assessed by extensive networks of neurite-bearing cells expressing $\beta$-III-tubulin (red) and Map-2 (green, shown in a 3-dimentional matrix). Arrows indicate pigmented cells typical of those in the CNS. All cells are shown by DAPI staining of their nuclei (blue) in the insets. Scale bars: $0.1 \mathrm{~mm}$.

\section{Discussion}

One of the major challenges for both developmental study and clinical translation has been how to channel the broad differentiation potential of pluripotent human stem cells to a desired phenotype efficiently and predictably. Although such cells can differentiate spontaneously in vitro into cells of all germ layers by going through a multi-lineage aggregate stage, only a small fraction of cells pursue a given lineage ${ }^{1,4}$. In those $\mathrm{hESC}$ derived aggregates, the simultaneous appearance of a substantial amount of widely divergent undesired cell types that may reside in three embryonic germ layers often makes the emergence of desired phenotypes not only inefficient, but uncontrollable and unreliable as well. Although cardiac and neural lineages have been derived in previous reports, however, the inefficiency in generating specialized cells through germ-layerinduction of pluripotent cells and the high risk of tumorigenicity following transplantation have hindered further clinical translation.

The hESC lines initially were derived and maintained in co-culture with growth-arrested mouse embryonic fibroblasts (MEFs) ${ }^{4}$. Although several human feeder, feeder-free, and chemically-formulated culture systems have been developed for hESCs ${ }^{11-13}$, the elements necessary and sufficient for sustaining the self-renewal of human pluripotent cells remain unsolved. These exogenous feeder cells and biological reagents help maintain the long-term stable growth of undifferentiated hESCs whereas mask the ability of pluripotent cells to respond to developmental signals. Maintaining undifferentiated hESCs in a defined biologics-free culture system that allows faithful expansion and controllable direct differentiation is one of the keys to their therapeutic utility and potential. RA was not sufficient to induce neuronal differentiation of undifferentiated hESCs maintained under previously-reported conditions containing exogenous feeder cells. Although neural lineages appear at a relatively early stage in hESC differentiation, treating hESC-differentiated multi-lineage aggregates (embryoid bodies) with RA only slightly increased the low yield of neurons ${ }^{1,14,15}$. In order to achieve uniformly conversion of human pluripotent stem cells to a particular lineage, we employed a defined culture system capable of insuring the proliferation of undifferentiated hESCs to identify conditions for well-controlled efficient induction of pluripotent hESCs exclusively to a particular clinically-relevant lineage by simple provision of small molecules (Fig. 1, Fig. 2). Future studies will reveal genetic and epigenetic control molecules in human CNS development as alternatives, which may pave the way for small molecule- 
mediated direct control and modulation of hESC pluripotent fate when deriving clinically-relevant lineages for regenerative therapies. Without RA treatment, $1-5 \%$ hESCs will undergo spontaneous differentiation into neurons ${ }^{1,14,15}$. With RA treatment, we have been able to generate $>95 \%$ embryonic neuronal progenitors and neurons from hESCs maintained under a define culture in a process that might emulate human embryonic development ${ }^{14}$. Recently, known neural-fate determining genes have been used to transdifferentiate mouse fibroblasts into adult neural progenitors and neurons with a low efficiency ranging $0.5-8 \%{ }^{17}, 18$. However, reprogrammed somatic cells have historically been associated with abnormal gene expression and accelerated senescence with impaired therapeutic utility ${ }^{19-21}$. Finally, the protocol we established here is limited to pluripotent hESCs derived from the inner cell mass (ICM) or epiblast of the human blastocyst ${ }^{4}$, may not apply to other pluripotent cells, including animal-originated ESCs, ESCs derived from earlier morula (eight-cell)-stage embryos ${ }^{22}$, and artificially reprogrammed cells ${ }^{23}$.

\section{Disclosures}

The authors declare competing interests. XHP is the founder of Xcelthera. XHP and EYS have intellectual properties related to hESCs.

\section{Acknowledgements}

XHP has been supported by National Institute of Health (NIH) grants from National Institute on Aging (NIHK01AG024496) and The Eunice Kennedy Shriver National Institute of Child Health and Human Development (NIHR21HD056530).

\section{References}

1. Parsons, X.H., Teng, Y.D., \& Snyder, E.Y. Important precautions when deriving patient-specific neural elements from pluripotent cells. Cytotherapy. 11, 815-824 (2009)

2. Redmond, D.E., Jr, Bjugstad, K.B., Teng, Y.D., Ourednik, V., Ourednik, J., Wakeman, D.R., Parsons, X.H., Gonzalez, R., Blanchard, B.C., Kim, S.U., et al. Behavioral improvement in a primate Parkinson's model is associated with multiple homeostatic effects of human neural stem cells. Proc. Natl. Acad. Sci. U.S.A. 104, 12175-12180 (2007).

3. Martino, G. \& Pluchino, S. The therapeutic potential of neural stem cells. Nature Rev. 7, 395-406 (2006).

4. Thomson, J.A., Itskovitz-Eldor, J., Shapiro, S.S., Waknitz, M.A., Swiergiel., J.J., Marshall, V.S., \& Jones, J.M. Embryonic stem cell lines derived from human blastocysts. Science. 282, 1145-1147 (1998).

5. Zhang, S., Wernig, M., Duncan, I.D., Brustle, O., \& Thomson, J.A. In vitro differentiation of transplantable neural precursors from human embryonic stem cells. Nat. Biotechnol. 19, 1129-1133 (2001).

6. Koch, P., Opitz, T., Steinbeck, J.A., Ladewig, J., \& Brüstle, O. A rosette-type, self-renewing human ES cell-derived neural stem cell with potential for in vitro instruction and synaptic integration. Proc. Natl. Acad. Sci. U. S. A. 106, 3225-3230 (2009).

7. Elkabetz, Y., Panagiotakos, G., Al Shamy, G., Socci, N.D., Tabar, V., \& Studer, L. Human ES cell-derived neural rosettes reveal a functionally distinct early neural stem cell stage. Genes. Dev. 22, 152-165 (2008).

8. Aubry, L., Bugi, A., Lefort, N., Rousseau, F., Peschanski, M., \& Perrier, A.L. Striatal progenitors derived from human ES cells mature into DARPP32 neurons in vitro and in quinolinic acid-lesioned rats. Proc. Natl. Acad. Sci. U.S.A. 105, 16707-16712 (2008).

9. Roy, N.S., Cleren, C., Singh, S.K., Yang, L., Beal, M.F., \& Goldman, S.A. Functional engraftment of human ES cell-derived dopaminergic neurons enriched by coculture with telomerase-immortalized midbrain astrocytes. Nature. Medicine. 12, 1259-1268 (2006).

10. Wernig, M., Zhao, J.P., Pruszak, J., Hedlund, E., Fu, D., Soldner, F., Broccoli, V., Constantine-Paton, M., Isacson, O., \& Jaenisch, R. Neurons derived from reprogrammed fibroblasts functionally integrate into the fetal brain and improve symptoms of rats with Parkinson's disease. Proc. Natl. Acad. Sci. U.S.A. 105, 5856-5861 (2008).

11. Richards, M., Fong, C., Chan, W., Wong, P., \& Bongso, A. Human feeders support prolonged undifferentiated growth of human inner cell masses and embryonic stem cells. Nature. Biotechnol. 20, 933-936 (2002).

12. Xu, C., Inokuma, M.S., Denham, J., Golds, K., Kundu, P., Gold, J.D., \& Carpenter, M. Feeder-free growth of undifferentiated human embryonic stem cells. Nature. Biotechnol.. 19, 971-974 (2001).

13. Xu, R.H., Peck, R.M., Li, D.S., Feng, X., Ludwig, T., \& Thomson, J.A. Basic FGF and suppression of BMP signaling sustain undifferentiated proliferation of human ES cells. Nature. Methods. 2, 185-190 (2005).

14. Parsons, X.H., Teng, Y.D., Moore, D.A., \& Snyder, E.Y. Patents on technologies of human tissue and organ regeneration from pluripotent human embryonic stem cells. Recent Patents on Regenerative Medicine. 1, 142-163 (2011).

15. Schuldiner, M., Eiges, R., Eden, A., Yanuka, O., Itskovitz-Eldor, J., Goldstein, R.S., \& Benvenisty, N. Induced neuronal differentiation of human embryonic stem cells. Brain. Res. 913, 201-205 (2001).

16. Perrier, A.L., Tabar, V., Barberi, T., Rubio, M.E., Bruses, J., Topf, N., Harrison, N.L., \& Studer, L. Derivation of midbrain dopamine neurons from human embryonic stem cells. Proc. Natl. Acad. Sci. U.S.A. 101, 12543-12548 (2004).

17. Vierbuchen, T., Ostermeier, A., Pang, Z.P., Kokubu, Y., Südhof, T.C., \& Wernig, M. Direct conversion of fibroblasts to functional neurons by defined factors. Nature. 463, 1035-1041 (2010).

18. Kim, J., Efe, J.A., Zhu, S., Talantova, M., Yuan, X., Wang, S., Lipton, S.A., Zhang, K., \& Ding, S. Direct reprogramming of mouse fibroblasts to neural progenitors. Proc. Natl. Acad. Sci. U.S.A. 108, 7838-7843 (2011).

19. Kim, K., Doi, A., Wen, B., Ng, K., Zhao, R., Cahan, P., Kim, J., Aryee, M. J., Ji, H., \& Ehrlich, L.I. Epigenetic memory in induced pluripotent stem cells. Nature. 467, 285-290 (2010).

20. Gore, A., Li, Z., Fung, H.L., Young, J.E., Agarwal, S., Antosiewicz-Bourget, J., Canto, I., Giorgetti, A., Israel, M.A., Kiskinis, E., et al. Somatic coding mutations in human induced pluripotent stem cells. Nature. 471, 63-67 (2011).

21. Feng, Q., Lu, S.J., Klimanskaya, I., Gomes, I., Kim, D., Chung, Y., Honig, G.R., Kim, K.S., Lanza, \& R. Hemangioblastic derivatives from human induced pluripotent stem cells exhibit limited expansion and early senescence. Stem. Cells. 28, 704-712 (2010).

22. Klimanskaya, I., Chung, Y., Becker, S., Lu, S.-J., \& Lanza, R. Derivation of human embryonic stem cells from single blastomeres. Nat. Protocols. 2, 1963-1972 (2007). 
23. Park, I.H., Zhao, R., West, J.A., Yabuuchi, A., Huo, H., Ince, T.A., Lerou, P.H., Lensch, M.W., \& Daley, G.Q. Reprogramming of human somatic cells to pluripotency with defined factors. Nature. 451, 141-146 (2008). 